\title{
MODERNIDADE, DESCOLONIALIDADE E EDUCAÇÃO POPULAR: PERSPECTIVAS DA PEDAGOGIA DA ESPERANÇA DE PAULO FREIRE
}

\author{
Vera Lucia Ermida BARBOSA ${ }^{1}$
}

RESUMO: Este ensaio se insere no debate acerca da Reflexão Descolonial que vem realizando um movimento epistemológico fundamental para a renovação crítica e utópica das ciências sociais na América Latina no século XXI. Este cenário compõe o contexto onde se insere a Educação Popular como proposta pedagógica no século XX em contraponto aos processos de dominação inaugurados na América Latina a partir do seu 'descobrimento'. A atualidade do pensamento de Paulo Freire como referência epistemológica para a construção de uma práxis libertadora e sua articulação com a Reflexão Descolonial serão nosso eixo de análise na perspectiva de promover um diálogo entre elas no sentido de buscar uma interlocução entre suas propostas educativas/políticas/organizativas na emancipação do espelho eurocêntrico.

PALAVRAS-CHAVE: Modernidade. Descolonialidade. Educação popular. Pedagogia da Esperança.

\section{INTRODUÇÃO}

\author{
"O que não é possível é simplesmente fazer um discurso \\ democrático, antidiscriminatório e ter uma prática colonial." \\ Paulo Freire (2008, p.68).
}

Os imaginários híbridos do Sul põem em questão os fundamentos da narrativa unívoca e etnocentrada da Modernidade. A crise da racionalidade ocidental faz vacilar ainda com maior intensidade tais fundamentos, na medida em que se mostram cada vez menos capazez de cumprir os promessas que a haviam legitimado (paz, liberdade, igualdade, progresso, prosperidade, solidariedade etc.) (SANTOS, 2005).

A Reflexão Descolonial ${ }^{2}$ se insere neste debate trazendo a questão do eurocentrismo como centro do projeto modernidade/colonialidade, propondo a descolonização da história narrada e do pensamento historiográfico imperial. Segundo Arturo Escobar (2003), podemos dizer que para este grupo a força orientadora é uma

\footnotetext{
${ }^{1}$ Doutoranda em Estudos Contemporâneos. UC - Universidade de Coimbra. Instituto de Investigação Interdisciplinar - Centro de Estudos Interdisciplinares do Século 20. Doutoranda em Psicossociologia de Comunidades e Ecologia Social. UFRJ - Universidade Federal do Rio de Janeiro. Pós-graduação em Psicossociologia de Comunidades e Ecologia Social. Rio de Janeiro - RJ - Brasil. 22290-240 vera.ermida@outlook.com

${ }^{2}$ Embora o pensamento descolonial tenha sido implantado a partir do início da colonialidade, sua genealogia e seu nome foram recentemente propostos pôr intelectuais do grupo modernidade / colonialidade. Seus principais membros são: Walter Mignolo, Aníbal Quijano, Edgardo Lander, Ramón Grosfoguel, Santiago Castro-Gómez, Catherine Walsh, Nelson Maldonado-Torres, Zulma Palermo, Fernando Coronil, Eduardo Restrepo, Agustin Lao Montes, Freya Schiwy, Sajinés Javier e Jose David Saldívar.
} 
reflexão continuada sobre a realidade cultural e política latinoamericana, incluindo o conhecimento subalternizado dos grupos explorados e oprimidos.

$\mathrm{Na}$ perspectiva de construção de saberes, Mignolo (2003a) considera que a relação entre colonialidade e epistemologia aponta para o que chama de um 'paradigma outro' de pensamento crítico, analítico e utópico, distinto e complementar da 'transição paradigmática, ${ }^{3}$ apresentada por Boaventura Sousa Santos, e que partem da constatação do esgotamento do projeto da modernidade. Configuram-se a partir das epistemologias locais, geopoliticamente, e não universalmente. O 'paradigma outro' não é um novo paradigma que assenta nos processos da história moderna e ocidental. Trata-se de uma expressão que convoca e aglutina diferentes projetos da crítica da modernidade/colonialidade Europeia unidos por um pensamento fronteiriço, ou seja, um pensamento que identifica o potencial do pensamento que surge da subalternidade colonial, o espaço onde o pensamento foi negado pelo pensamento da modernidade, de esquerda ou de direita. O 'paradigma outro' configura-se como um pensamento diatópico ou pluritópico enfrentando, em conflito, os existentes (cristãos, liberais, marxistas e seus correspondentes 'neos' ou 'pós').

Nesta medida, a descolonização do poder, do saber e do ser se colocam como questão fundamental no pensamento descolonial e na busca de construir novas formas de expressão do poder, do conhecimento e da subjetividade a partir do Sul (MIGNOLO, 2010).

A Educação Popular dentro do paradigma latinoamericano surge em contraponto aos processos de dominação (econômica, política e cultural) advindos dos países centrais do capitalismo do século XX. A questão do conhecimento se constitui em um dos pontos centrais dos movimentos que promovem a Educação Popular como um projeto de emancipação dos oprimidos (FLEURI, 2002). Construída a partir dos saberes mobilizados na luta por reconhecimento e por dignidade, a Educação Popular assume diretrizes políticas de diversas orientações que convergem para o enfrentamento das situações desumanizadoras que a exploração fomenta no cenário capitalista. A obra de Paulo Freire é referência em suas concepções epistemológicas, políticas e éticas, oferecendo premissas teóricas que oportunizam a (re) construção do conhecimento a

${ }^{3}$ Sobre Transição Paradigmática Boaventura afirma que: “[...] por de baixo de um brilho aparente, a ciência moderna, que o projeto da modernidade considerou ser a solução privilegiada para a progressiva e global racionalização da vida social e individual, tem-se vindo a converter, ela própria num problema sem solução, gerador de recorrentes irracionalidades. Penso hoje que essa transição paradigmática, longe de se confinar ao domínio epistemológico, ocorre no plano societal global.” (SANTOS, 1997, p. 34). 
partir da realidade concreta das classes populares. A Pedagogia da Esperança (FREIRE, 2008) traz um diálogo do autor com a Pedagogia do Oprimido (FREIRE, 2003) e acrescenta atualidade ao método e reafirma a perspectiva da esperança na luta contra a opressão.

A atualidade do pesnamento de Paulo Freire como referência epistemológica surgida ao Sul para a construção de uma práxis libertadora e sua articulação com a Reflexão Descolonial serão nosso eixo de análise neste ensaio na perspectiva de promover um diálogo entre elas no sentido de buscar uma interlocução entre suas propostas educativas/políticas/organizativas na emancipação do espelho eurocêntrico.

\section{A MODERNIDADE NA PERSPECTIVA DESCOLONIAL}

A partir da década de noventa teve início nos países da América do Sul e Caribe a Reflexão Descolonial, um "programa de investigação" (ESCOBAR, 2003, p.53, tradução nossa), que compartilha noções, raciocínios e conceitos que lhe conferem uma identidade e um vocabulário próprio, contribuindo para a renovação analítica e utópica das ciências sociais latino-americanas do século XXI. ${ }^{4}$

Esta construção epistemológica conforma uma coletividade de argumentações ao redor de um conjunto de problematizações da modernidade e particularmente desta experiência na perspectiva do subalterno. No campo das chamadas epistemologias do Sul (SANTOS, 2009), que questiona por que razão, nos dois últimos séculos, dominou uma epistemologia que eliminou da reflexão epistemológica o contexto cultural e político da produção e reprodução do conhecimento e as consequências desta descontextualização, a reflexão descolonial se refere a experiências e trajetórias intelectuais e políticas da América Latina (a partir da experiência colonial hispanolusitana e das correntes intelectuais como a teoria da dependência e a filosofia da libertação) ${ }^{5}$.

Na perspectiva descolonial a modernidade se ancora, ou é ela própria, na/a história do imperialismo, sendo, não um período histórico, mas uma auto narrativa dos sujeitos e das instituições que assumiram o protagonismo como se fosse o centro, a referência mundial, a partir do século XV. O autorrelato da modernidade, em que o protagonismo se fundamenta como referência de benefício para todo o mundo através

${ }_{5}^{4}$ Sobre a constituição do grupo Modernidade/Colonialidade ver: Ballestrin (2013).

${ }^{5}$ Para algumas referências ilustrativas desta problemática, ver as obras de Enrique Dussel, Walter Mignolo, Aníbal Quijano, Santiago Castro-Gómez, Eduardo Mendieta, Edgardo Lander; Nelson Maldonado Torres e Immanuel Wallerstein. 
da conversão ao cristianismo, da missão civilizadora francesa e inglesa a partir do século XVII e do projeto de modernização e desenvolvimento após a Segunda Guerra Mundial, é a justificativa da expansão imperial dos Estados Monárquicos e seculares, europeus do Atlântico (MIGNOLO, 2010). Nesta perspectiva, a América Latina se configura como uma invenção neste autorrelato da modernidade, que está inserida no âmbito histórico/colonial segundo a teoria do sistema-mundo ${ }^{6}$ defendida por Wallerstein (1992), que considera o capitalismo como um processo histórico que não resulta de uma história linear que se desenvolve de maneira natural, mas o resultado das múltiplas interações de um conjunto de fenômenos que o fazem possível. Assim, o 'descobrimento' da América se converte no início do processo de expansão global do capitalismo, da ciência e do sistema interestatal, entre outros aspectos, que marca a história até os dias de hoje e que é marcado pela colonialidade ${ }^{7}$.

Quijano (2014) considera que a colonialidade se localiza no interior da globalização ${ }^{8}$ em curso, sendo parte do processo que deu origem a ela e que:

Teve início com a constituição da América Latina e do capitalismo colonial/moderno e eurocentrado como novo padrão de poder mundial sobre a ideia de raça, uma construção mental que expressa a experiência básica da dominação colonial e que desde então permeia as dimensões mais importantes do poder mundial, incluindo sua racionalidade específica, o eurocentrismo. (QUIJANO, 2014, p.109, tradução nossa).

A descolonialidade surge como o terceiro elemento da modernidade/colonialidade. Para Mignolo, “[...] a conceptualização mesma da colonialidade como constitutiva da modernidade é já o pensamento descolonial em marcha.” (MIGNOLO, 2007, p.249, tradução nossa).

Os pensamentos descoloniais se inscrevem a partir da crítica da narrativa convencional da Modernidade, elaboram novos projetos de ser, estar e viver juntos que não são somente contra hegemônicos, mas integrativos, preferindo à visão pós-moderna da globalização mercantil uma "transmodernidade" (DUSSEL, 1994) emancipadora, liberando as potencialidades alternativas dos "Outros" que haviam sido negados ou ocultados até agora. Não se trata somente de desvelar ou de rejeitar a mistificação

\footnotetext{
${ }^{6}$ Immanuel Wallerstein em sua teoria do sistema-mundo desenvolve uma proposta para a análise do capitalismo como sistema mundial o qual considera um processo histórico que não resulta de uma história linear que se desenvolve de maneira natural, mas o resultado das múltiplas interações de um conjunto de fenômenos que o fazem possível e que faz que sejam Espanha e Portugal os países encarregados de seu primeiro impulso.

${ }^{7}$ O conceito de colonialidade foi elaborado pela primeira vez por Aníbal Quijano (1991).

${ }^{8}$ Sobre o conceito de Globalização ver: Santos (2005).
} 
cultural eurocêntrica, mas de abarcá-la num conjunto genérico mais aberto, no qual se admitem todas as racionalidades num espaço de diálogos múltiplos.

Pensar o Outro, desde o Outro, desde sua perspectiva subalterna, promovendo o que Quijano (1992) chamou primeiro de "descolonização epistemológica" e Walter Mignolo (2010), depois, de "desobediência epistêmica", nisso residem os pensamentos descoloniais surgidos como possibilidades transformadoras e emancipadoras, alternativas aos processos da Modernidade colonial "[...] para intercambiar experiências e significações, como fundamento para una racionalidade-outra." (MIGNOLO, 2010, p.125, tradução nossa).

\section{A DESCOLONIALIDADE DO PODER, DO SABER E DO SER ${ }^{9}$}

Para Quijano (1992), com o “descobrimento" da América e a subsequente colonização, se forja um novo padrão de poder mundial na qual a modernidade europeia marca de maneira inexpugnável a colonialidade nas periferias.

Mignolo (2010, p.12, tradução nossa) sugere que a matriz colonial do poder "é uma estrutura complexa de níveis entrelaçados" na qual a colonialidade se reproduz em uma tripla dimensão: a do poder, do saber e do $\operatorname{ser}^{10}$, sendo a colonialidade o lado obscuro e necessário da modernidade; é a sua parte indissociavelmente constitutiva (MIGNOLO, 2003a).
A expressão "colonialidade do poder" designa um processo fundamental de estruturação do sistema-mundo moderno/colonial, que articula os lugares periféricos da divisão internacional do trabalho com a hierarquia étnico-racial global e com a inscrição de migrantes do Terceiro Mundo na hierarquia étnico-racial das cidades metropolitanas globais. Os Estados-nação periféricos e os povos não europeus vivem hoje sob o regime da "colonialidade global" imposto pelos Estados Unidos, através do Fundo Monetário Internacional, do Banco Mundial, do Pentágono e da OTAN. As zonas periféricas mantêm-se numa situação colonial, ainda que já não estejam sujeitas a uma administração colonial. (GROSFOGUEL, 2008, p.126).

Mignolo (2010, p.12, tradução nossa) sugere que a matriz colonial do poder "é uma estrutura complexa de níveis entrelaçados" na qual a colonialidade se reproduz em uma tripla dimensão: a do poder, do saber e do ser, sendo a colonialidade o lado

\footnotetext{
${ }^{9}$ Esta reflexão é a base do conceito de Giro Descolonial proposto pela Reflexão Descolonial. A este respeito ver: Castro-Gómes y Grosfoguel (2007).

${ }^{10}$ A Colonialidade do Poder e do Saber ganhou várias elaborações do grupo, enquanto que a Colonialidade do Ser, primeiramente pensada por Mignolo foi posteriormente desenvolvida por Maldonado-Torres (2008).
} 
obscuro e necessário da modernidade; é a sua parte indissociavelmente constitutiva (MIGNOLO, 2003a).

La genealogía del pensamiento decolonial se estructura en el espacio planetario de la expansión colonial/imperial, contrario a la genealogía de la modernidad europea [...] la genealogía del pensamiento decolonial es pluriversal (no universal). Así, cada nudo de la red de esta genealogía es un punto de despegue y apertura que reintroduce lenguas, memorias, economías, organizaciones sociales, subjetividades, esplendores y miserias de los legados imperiales. (MIGNOLO, 2007, p.45, tradução nossa).

A raça como princípio de organização social e o capitalismo como modo de controle operacional constituem, segundo Aníbal Quijano (2000), são os dois pilares da colonialidade do poder. São as bases políticas e econômicas que determinaram e continuam moldando ainda as realidades sociais de América Latina, após ter embebido todas as estruturas simbólicas e epistêmicas que regem os intercâmbios culturais e a produção de conhecimentos. Desde o século XVII, o mundo [ocidental] (Descartes, Espinosa, Locke, Newton...).

[...] foi elaborando e formalizando uma forma de produzir conhecimento que satisfazia as necessidades cognitivas do capitalismo: a medição, quantificação, a interiorização (ou objetivação) do que é cognoscível sobre o conhecedor, para controlar as relações dos homens com a natureza e entre aqueles em relação a esta, em especial a propriedade dos recursos de produção. (QUIJANO, 2000, p.343, tradução nossa).

As humanidades e as ciências, através das suas práticas e postulados, não deixaram de adotar, quase sem questionar, esse modo de pensar o conhecimento, de transmiti-lo e de aplicá-lo como modelo de progresso e de crescimento.

As ciências sociais ocidentais da segunda etapa da expansão colonial estabeleceram maneiras particulares de conhecer e representar os lugares dominados em benefício do acidente e como forma de justificar sua atuação política e econômica. Em ambas as etapas da modernidade o conhecimento foi sempre uma ferramenta indispensável da justificativa ideológica de colonização (MIGNOLO, 2010). A ciência moderna produz objetos de conhecimento tais como "América", "Índias Ocidentais", “América Latina” ou "Terceiro Mundo", que funcionaram na realidade como estratégias coloniais de subalternização (CASTRO-GÓMES; GROSFOGUEL, 2007). ${ }^{11}$

${ }^{11}$ Sobre esta temática ver também Said (2007). 
Nesta perspectiva, a razão moderna segundo Mignolo (2007) estabelece o locus de enunciação que, em nome da racionalidade, da ciência e da filosofia afirmou seu próprio privilégio sobre outras formas de racionalidade e sobre formas de pensamento. Assim, os modos de construção do conhecimento estão imbricados com os 'lugares' de onde este conhecimento se elabora, ou seja, o lugar de enunciação das disciplinas é precisamente um lugar geopoliticamente marcado. A importância em se considerar os 'lugares de enunciação' é fundamental para a construção de uma crítica às pretensões universalistas atribuídas ao conhecimento ocidental, no qual um imaginário generalizado, a partir da modernidade europeia, se auto elegeu o imaginário do 'ser humano', que sustentou um imaginário linear e progressista da história onde a modernidade é um processo contínuo e necessário da evolução humana. Esta ideologia epistemológica de cunho universalista do saber oculta sua 'localização' e consequentemente, subalterniza outros saberes locais não europeus.

A 'geopolítica do conhecimento' 12 se apresenta para o autor como a forma de romper com esta atopia do saber.

Los lugares de enunciación generan, por un lado, las geopolíticas del conocimiento en sus diversas y complejas relaciones con los diversos imperialismos occidentales [...] y, por otro, las condiciones para la toma de decisiones éticas, políticas y epistémicas para la descolonización del saber y la contribución a crear un mundo críticamente cosmopolita. (MIGNOLO, 2003a, p.54).

A emergência de saberes plurais, não hegemônicos e locais favorece a construção de saberes plurais, construções outras do mundo, da vida, da política e do ser.

A colonialidade do ser é um conceito desenvolvido por Maldonado-Torres (2008) a partir de Quijano, Levinas, Fanon e outros filósofos. O autor afirma que "[...] a colonialidade do Ser terá de se referir não apenas a um acontecimento de violência originário, mas também ao desenrolar da história moderna em termos de uma lógica da colonialidade [...]" (MALDONADO-TORRES, 2008, p.18) onde um "ser colonizado" foi violentamente separado do ser pensado na Europa, um "ser colonizado" que é visto como inferior (19). Quijano (2000) discute como através do exercício do poder surgem categorias que identificam os sujeitos como, por exemplo, as categorias de europeus,

\footnotetext{
${ }^{12}$ Mignolo (2003b) argumenta que "[...] a América Latina é um resultado e um produto da geopolítica do conhecimento, isto é, o conhecimento geopolítico feito e imposto pela modernidade em sua autodefinição como modernidade. Neste sentido, a América Latina foi tomada como algo deslocado da modernidade, um deslocamento que assumiu os intelectuais e estadistas latino-americanos e se esforçou para tornar-se moderno como se modernidade fosse um ponto de chegada e não justificação da colonialidade do poder."
} 
índios e negros. O autor demonstra como o poder, naturaliza essas categorias, tornando algumas superiores e outras inferiores. "Em consequência, é tempo de aprender a liberar-nos do espelho eurocêntrico onde a nossa imagem é sempre, necessariamente, destorcida. É tempo, enfim, de deixar de ser o que não somos [...]" (QUIJANO, 2000, p.242, tradução nossa).

\section{EDUCAÇÃO POPULAR E A CONSTRUÇÃO POLÍTICA DO SER}

Ao longo da segunda metade do século XX muitas experiências ligadas à concepção de Educação Popular se desenvolveram na América Latina. Essa diversidade de movimentos sob essa denominação não permite conceituar de forma precisa o que seja Educação Popular. Contudo, o exame histórico desse campo nos direciona para pelo menos três movimentos que se entrecruzam desde o começo do século XX: em primeiro lugar, os trabalhos de educação escolar e práticas de formação de quadros entre os operários. Em segundo lugar, o movimento de educadores e intelectuais pela escola pública e pela democratização derivada da educação. Em terceiro lugar, os movimentos e campanhas de alfabetização de adultos (FLEURI, 2002).

A constituição do método da Educação Popular começa a se estruturar como corpo teórico e prática social no Brasil no final da década de 1950, quando intelectuais e educadores ligados à Igreja Católica e influenciados pelo humanismo personalista que florescia na Europa no pós-guerra se voltaram para as questões populares. Paulo Freire foi o pioneiro no trabalho de sistematização teórica de Educação Popular com o livro Pedagogia do oprimido (1966- 2003).

Um elemento fundamental do método é o fato de considerar, como ponto de partida do processo pedagógico, o saber anterior do educando, ou seja, o entendimento adquirido sobre a inserção social e na natureza que as experiências de trabalho, vida social, luta pela sobrevivência e pela transformação da realidade proporcionam. Esse conhecimento fragmentado e pouco elaborado é a matéria-prima da Educação Popular. A valorização do saber e valores do educando permitem familiaridade com o processo educativo, neste sentido, não se reproduz a passividade usual dos processos pedagógicos tradicionais. Na Educação Popular não basta que o conteúdo discutido seja revolucionário, é necessário superar o processo de discussão verticalizado e que enfatiza o processo de transmissão de conhecimento. É preciso que amplie os espaços de interação cultural e negociação entre os diversos atores envolvidos em determinado 
problema social, para a construção compartilhada do conhecimento e da organização política. Ao invés de procurar difundir conceitos e comportamentos considerados corretos, procura problematizar, em uma discussão aberta, o que está incomodando e oprimindo. Prioriza a relação com os movimentos sociais por ser expressão mais elaborada dos interesses e da lógica dos setores subalternos da sociedade, cuja voz é usualmente desqualificada nos diálogos e negociações. Para Santos (2003, p. 22-23),

[...] a educação devia ser uma criação constante de subjetividades paradigmáticas, porque para criar subjetividades não-paradigmáticas não é preciso escola para coisa nenhuma; para isso basta deixar andar as crianças por aí, aprendem mais fora das escolas do que nas escolas até porque na escola têm que desaprender muitas coisas. [...] Aqueles que nelas [as escolas] trabalham também tem que se sentir menos como funcionários do presente e muito mais como funcionários do futuro, se é que a palavra funcionário se pode aplicar adequadamente ao futuro, penso bem que não.

A Educação Popular pode ser entendida como um esforço de mobilização, organização e capacitação das classes populares; capacitação científica e técnica.

Neste sentido é fundamental relacionar as dimensões educativas com as históricas, com o compromisso explícito de que tratar das coisas do passado é descobrir as vidas e os pensamentos das pessoas comuns e resgatá-las. Assim, no presente, “[...] nosso problema é também o de desnudar as suposições igualmente presunçosas daqueles que pensam saber o que são os fatos e as soluções, e que querem impô-las às pessoas" (HOBSBAWM, 1998, p.230).

Nesta perspectiva o conhecimento crítico desconstrói a historicidade de ser e saber revela os limites e possibilidades em cada situação, desnaturaliza ideologias dominantes que invadem a experiência e ilumina as dinâmicas formativas constituintes do eu.

A construção política do Ser necessita basear-se numa “[...] pedagogia verdadeiramente crítica, acolhendo com maior totalidade a importância da intuição, dos sentimentos, e das emoções por sua importância epistemológica e também por sua importância no alcance de um modo saudável de ser no mundo.” (GLASS, 2013, p.840). O que, nas palavras de Freire se afirmaram como:

A consciência do mundo que implica a consciência de mim no mundo, com ele e com os outros, que implica também a nossa capacidade de perceber o mundo, de compreendê-lo, não se reduz a uma experiência racionalista. É como uma totalidade - razão, sentimentos, emoções, 
desejos - que meu corpo consciente do mundo e de mim capta o mundo a que se intenciona. (FREIRE, 1995, p.75-76).

\section{A ESPERANÇA COMO INSTRUMENTO DA PEDAGOGIA}

"Não sou esperançoso por pura teimosia, mas por imperativo existencial e histórico."

Paulo Freire (2008, p.10).

A relação entre luta e esperança é particularmente desenvolvida por Paulo Freire (2008) em seu livro Pedagogia da Esperança em que o autor promove um reencontro com a Pedagogia do Oprimido (1966-2003). Neste reencontro reafirma sua 'opção' pela esperança na luta na perspectiva de que a esperança sem a luta é ingenuidade e a luta sem a esperança é "frívola ilusão". Defende ainda que, não nascemos esperançosos. Por isso precisamos de uma educação para a esperança e uma pedagogia da esperança.

Pensar que a esperança sozinha transforma o mundo e atuar movido por tal ingenuidade é um modo excelente de tombar na desesperança, no pessimismo, no fatalismo. Mas prescindir da esperança na luta para melhorar o mundo, como se a luta se pudesse reduzir a atos calculados apenas, a pura cientificidade, é frívola ilusão. Prescindir da esperança que se funda também na verdade como na qualidade ética da luta é negar a ela um dos seus suportes fundamentais. [...] Enquanto necessidade ontológica, a esperança precisa da prática para tornar-se concretude histórica. É por isso que não há esperança na pura espera, nem tampouco se alcança o que se espera na espera pura, que vira, assim, espera vã.

Sem um mínimo de esperança não podemos sequer começar o embate, mas, sem o embate, a esperança, como necessidade ontológica, se desendereça e se torna desesperança que, às vezes, se alonga em trágico desespero. Daí a precisão de uma certa educação da esperança. É que ela tem uma tal importância em nossa existência, individual e social, que não devemos experimentá-la de forma errada, deixando que ela resvale para a desesperança e o desespero. Desesperança e desespero, consequência e razão de ser da inação ou do imobilismo. (FREIRE, 2008, p.10-11).

A pedagogia da esperança como concepção da educação e a pedagogia da luta são inseparáveis no pensamento de Paulo Freire assim como são também inseparáveis de sua teoria do conhecimento e de sua concepção de educação.

Na perspectiva freireana, o objetivo é aliar educação a um projeto histórico de emancipação social: as práticas educacionais deveriam estar relacionadas a uma teoria do conhecimento. Consequentemente, a educação aparece como ato de conhecer e não como uma simples transmissão do conhecimento ou bagagem cultural de sociedade. Assim, uma vez que conhecimento e poder são considerados 
intimamente ligados, tradições e práticas culturais no ensino, por exemplo, estão sob suspeita de dissimular relações de dominação. (TORRES, 1997, p. 70).

A teoria e a práxis de Paulo Freire cruzaram as fronteiras das disciplinas, das ciências e dos espaços geográficos. Ao mesmo tempo em que as suas reflexões foram aprofundando o tema que ele perseguiu por toda a vida - a educação como prática da liberdade $^{13}$ - suas abordagens transbordaram-se para outros campos do conhecimento, criando raízes nos mais variados solos, fortalecendo teorias e práticas educacionais num exercício de pensamento transdisciplinar não apenas atual, mas necessário.

Esta pedagogia planetária, como definida por Dussel (2002), se propõe o surgimento de uma consciência ético-crítica. Uma ação educadora que busca não só uma melhoria cognitiva, mas a produção de uma consciência ético-crítica que se origina no próprio sujeito, que por ser sujeito histórico é privilegiado de sua própria libertação. Deste modo, o ato pedagógico crítico se exerce no próprio sujeito e na sua práxis de transformação. A libertação, assim, é o lugar e o propósito desta pedagogia.

\section{CONCLUSÃO}

A Reflexão Descolonial e sua perspectiva de argumentações acerca de conjunto de problematizações da modernidade e particularmente desta experiência na perspectiva do subalterno parecem reforçar a insistência de Paulo Freire de que a curiosidade e a busca/pesquisa incansável formam o âmago de nosso ser epistemológico e, assim, a educação como prática de liberdade deve continuar aberta à multiplicidade de conhecimentos e comprometida com uma avaliação continuada de todas as formas de saber. Uma consciência crítica incorporada não é estritamente a posse ou alcance de um indivíduo, nem pode ser testada fora dos atos-limite situados dentro de horizontes culturais e históricos específicos (FREIRE, 2008), de modo que estes processos colaborativos pragmáticos constituem os únicos controles possíveis de nosso saber.

A descolonização como contínua produção democrática da existência social, contra toda forma de dominação e exploração deve estar apoiada também em uma práxis pedagógica, que não se encerre numa ação disciplinar, mas que esteja presente e de forma também contínua na orientação das práticas sociais. Numa pedagogia que traga em seu bojo sentimentos como a raiva e o amor, sem os quais não há esperança. "Uma defesa da tolerância, que não se confunde com a conivência, da radicalidade; uma

${ }^{13}$ Sobre este tema ver Freire (1999). 
crítica ao sectarismo, uma compreensão da pós-modernidade progressista e uma recusa à conservadora, neoliberal.” (FREIRE, 2008, p.12).

Uma Pedagogia de Esperanças.

\section{MODERNITY, DESCOLONIALITY AND POPULAR EDUCATION: PERPECTIVES OF PAULO FREIRE'S PEDAGOGY OF HOPE}

ABSTRACT: This paper inserts itself on the debate about the Descolonial reflection, which has been carrying out a fundamental epistemological movement for a critical and utopic renovation of social sciences in Latin America in the twentieth-first century. This scenario composes the context which includes Popular Education as a pedagogical proposal in the twentieth century as opposed to the processes of domination inaugurated in Latin America from its 'discovery'. The contemporaneity of Paulo Freire thought as an epistemological reference for the construction of a liberating praxis and its articulation with the Descolonial reflection will be our analysis axis so as to promote a dialogue between them in order to seek a conection between their educational proposals / policies / organizational empowerment in the Eurocentric mirror.

KEYWORDS: Modernity. Descoloniality. Popular education. Pedagogy of Hope.

\section{REFERÊNCIAS}

BALLESTRIN, L. América Latina e o giro decolonial. Revista Brasileira de Ciência Política, Brasília, n.11, p. 89-117, 2013. Disponível em:

<http://www.scielo.br/pdf/rbcpol/n11/04.pdf>. Acesso em: 26 maio 2015.

CASTRO-GÓMEZ, S.; GROSFOGUEL, R. Prólogo: giro decolonial, teoría y pensamiento heterárquico. In: CASTRO-GÓMEZ, S; GROSFOGUEL, R. El giro decolonial: reflexiones para una diversidad epistémica más allá del capitalismo global. Bogotá: Iesco-Pensar-Siglo del Hombre, 2007. p.9-23.

DUSSEL, E. Ética da libertação na idade da globalização e da exclusão. Petrópolis: Vozes, 2002.

El encubrimiento del otro: hacia el origem del mito de la modernidad. La Paz: Facultad de Humanidades y Ciencias de la educación, Universidad Mayor de San Andrés ; Plural Editores, 1994.

ESCOBAR, A. Mundos y conocimientos de otro modo: el programa de investigación modernidad/colonialidad latinoamericano. Tabula Rasa, Bogotá, n.1, p.58-86, 2003. 
FLEURI, R. A questão do conhecimento na educação popular: uma avaliação do seminário permanente de Educação Popular e de suas implicações epistemológicas. Ijuí: Unijuí, 2002.

FREIRE, P. Pedagigia da esperança: um reencontro com a Pedagogia do oprimido. São Paulo: Paz e Terra, 2008.

Pedagogia do oprimido. Rio de Janeiro: Paz e Terra, 2003.

Educação como prática da liberdade. Rio de Janeiro: Paz e Terra, 1999. À sombra desta mangueira. São Paulo: Olho D'água, 1995.

GLASS, D. R. Revisitando os fundamentos da educação para a libertação: o legado de Paulo Freire. Educação \& Realidade, Porto Alegre, v. 38, n. 3, p. 831-851, jul./set. 2013. Disponível em: <http://www.scielo.br/pdf/edreal/v38n3/08.pdf>. Acesso em: 28 maio 2015.

GROSFOGUEL, R. Para descolonizar os estudos de economia política e os estudos póscoloniais: transmodernidade, pensamento de fronteira e colonialidade global. Revista Crítica de Ciências Sociais, Coimbra, n. 80, p.115-147, 2008.

HOBSBAWN, E. Sobre história. São Paulo: Cia. das Letras, 1998.

MALDONADO-TORRES, N. A topologia do Ser e a geopolítica do conhecimento: modernidade e império. Revista Crítica da Ciências Sociais,Coimbra, n. 80, p.71-114, 2008 .

MIGNOLO,W. D. Desobediencia epistémica: retórica de la modernidad, lógica de la colonialidad Y gramática de la descolonialidad. Buenos Aires: Ediciones del Signo, 2010.

La idea de América Latina: la herida colonial y la opción decolonial. Barcelona: GEDISA, 2007.

Historias locales/dieños globales: colonialidad, conocimientos subalternos y pensamiento fronterizo. Madrid: Akal, 2003a.

. Las geopolíticas del conocimiento y colonialidad del poder. Entrevistadora:

Catherine Walsh. Polis: Revista Latinoamericana, [S.1.], v.4, 2003b. Disponível em: http://polis.revues.org/7138. Acesso em: 26 maio 2015.

QUIJANO, A. Textos de fundación. Buenos Aires: Ediciones del Signo, 2014.

Colonialidad del poder, eurocentrismo y América Latina. Buenos Aires: CLACSO, 2000.

Colonialidad y modernidad-racionalidad. In: HERACLIO, B. Les conquistados: 1492 y la población indígena de las Américas. Bogotá: Tercer Mundo Editores, 1992. p.437-447. 
Colonialidad y modernidad racionalidad. Perú Indígena, Lima. v.13, n.29, p.11-20, 1991.

SAID, E. W. Orientalismo: o Oriente como invenção do Ocidente. São Paulo:

Companhia de Bolso, 2007.

SANTOS, B. S. Una epistemología del Sur: la reinveición del conocimiento y la emancipación social. México: CLACSO, 2009.

Globalização: fatalidade ou utopia? Porto: Afrontamento, 2005.

Dilemas do nosso tempo: globalização, multiculturalismo e conhecimento. Entrevistadores: Luís Armando Gandin e Álvaro Moreira Hypolito. Currículo sem Fronteiras, [S.1.], v.3, n.2, p.5-23, 2003. Disponível em:

$<$ http://www.boaventuradesousasantos.pt/documentos/curriculosemfronteiras.pdf $>$. Acesso em: 5 out. 2015.

Pela mão de Alice: o social e o político na pós-modernidade. 4.ed. São Paulo: Cortez, 1997.

TORRES, C. A. Pedagogia da luta: da pedagogia do oprimido à escola pública popular. Campinas: Papirus, 1997.

WALLERSTEIN, I. Creación del sistema mundial moderno. In: PEÑA, L. B. Un mundo jamás imaginado. Bogotá: Santillana, 1992. p.201-209. 